\title{
EDITORIAL
}

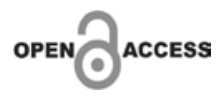

\section{O Sal e as Doenças Cardiovasculares}

\author{
Salt and Cardiovascular Disease \\ Gilson Soares Feitosa ${ }^{*}$ \\ ${ }^{1}$ Diretor de Ensino e Pesquisa do Hospital Santa Izabel, Editor-Chefe da Revista \\ Cientifica Hospital Santa Izabel; Salvador, Bahia, Brasil
}

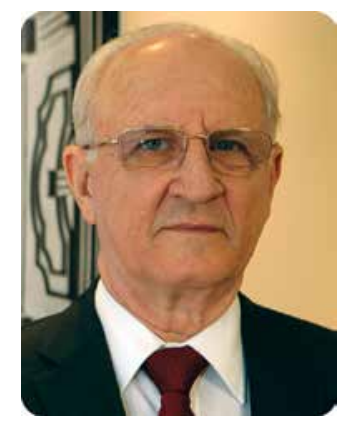

O reconhecimento da importância do sal na conservação dos alimentos tornou-se importante para os humanos que se aglomeravam em cidades e seus arredores há milhares de anos.

Com a industrialização de alimentos que se acentuou no século 19 houve um salto quantitativo nesse consumo.

No Brasil, um estudo realizado em 55.970 domicílios traz a estimativa média de um consumo de sódio de $4,7 \mathrm{~g} / \mathrm{pessoa} /$ dia, sendo maior no Nordeste do que no Sudeste.

Saliente-se que $2 \mathrm{~g}$ de sódio estão contidos em $5 \mathrm{~g}$ de sal de cozinha e, portanto, a média de consumo de sal vista no estudo foi ao redor de $12 \mathrm{~g}$ por pessoa por dia, o que excede em muito o recomendado para pessoas (consumo de $5 \mathrm{~g}$ ou menos de sal por dia). Isto equivale a uma porção de sal de cozinha contida em uma colher de chá $(5 \mathrm{~mL})$, cheia até a borda.

Tal quantidade é recomendada para o uso no total de refeições do dia, o que significa não acrescentar sal à mesa e fazendo-o apenas no preparo das alimentações, e ainda evitar o consumo de alimentos naturalmente salgados. $\mathrm{Ou}$, de outra maneira, cozinhar os alimentos naturais e somente acrescentar o sal à mesa em um total de uma colher de chá de sal dividida nas três refeições diárias.

Em termos populacionais, tal medida reduz em até $6 \mathrm{mmHg}$ a pressão arterial sistólica e $2,5 \mathrm{mmHg}$ a pressão arterial diastólica, traduzindo-se em benefícios esperados para a população em geral e podendo até mesmo melhorar em casos individuais em que a hipertensão arterial esteja presente.

$\mathrm{Na}$ maior parte, os estudos que apontam para isto são realizados na

Correspondence addresses: Dr. Gilson Soares Feitosa gilson-feitosa@uol.com.br

\section{Copyright}

(C) 2021 by Santa Casa de Misericórdia da Bahia. All rights reserved. ISSN: 2526-5563 e-ISSN: 2764-2089 DOI: 10.35753 população em geral fruto de estudos observacionais. Por outro lado, até que a educação do paladar para alimentos com menos sal ocorra, muitos se queixam do gosto insosso da comida. Daí então surgirem os substitutos de sal que reduzem a quantidade de sal e tentam reproduzir o gosto do alimento.

Recentemente, um estudo de grande relevância, o Salt Substitute and Stroke Trial (SSaSS), foi realizado em 600 cidades rurais da China e, pela primeira vez, testou-se, de maneira apropriada, em 20.995 pacientes, durante 4,74 anos, o efeito do uso de um substituto do sal em comparação com o grupo controle que mantiveram o seu uso regular de sal de cozinha de forma habitual da região. 
Os pacientes incluídos eram indivíduos que tivessem tido um acidente vascular cerebral ou que fossem hipertensos, maiores do que 60 anos de idade. O substituto de sal foi constituído de um produto que continha $75 \%$ de sódio $25 \%$ de potássio e foi utilizado na preparação de todas as alimentações. Isso foi então comparado com o grupo controle de consumo habitual de uso de sal, conforme o costume da região.

Verificou-se uma significativa redução de acidente vascular cerebral, eventos cardiovasculares e mortalidade total no grupo que fez uso do substituto de sal. Registre-se também que não houve eventos atribuíveis a uma hipercalemia.

Este estudo sugere uma maneira adequada de ajustar o consumo de sal com o auxílio de substitutos desde que a composição desse produto reproduza aquilo que foi visto no estudo ( $75 \%$ de sódio e $25 \%$ de potássio).

Convém salientar que indivíduos foram excluídos se tivessem insuficiência renal ou se fizessem uso de diuréticos poupadores de potássio.

A quantidade de substituto do sal liberado para o consumo diário por pessoa foi da ordem de 20 gramas, o que faz supor que o consumo de sal na dieta da população regional rural da China seja elevada.

Seria importante que este estudo fosse reproduzido em outras populações para que tivesse maior generalidade de emprego de suas conclusões. Ainda assim, esse estudo teve grande repercussão quando apresentado no Encontro Anual da American College of Cardiology (ACC) porque abre a possibilidade de que se possa ajudar pacientes nessa tarefa de reduzir o consumo total de sal com uso de substitutos até que seu paladar seja reeducado de modo a atingir um nível de satisfação com quantidade menor de sal na dieta.

\section{Referência}

1. Andrade SSA, Stopa SR, Brito AS, Chueri PS, Szwarcwald CL, Malta DC. Prevalência de hipertensão arterial autorreferida na população brasileira: análise da Pesquisa Nacional de Saúde, 2013. Epidemiol Serv Saúde 2015;24(2):297-304.

2. Neal B, Wu Y, Feng X, et al. Effect of salt substitution on cardiovascular events and death. N Engl J Med 2021;385:1067-1077. 